\title{
ENSINO DE PROJETO DE ARQUITETURA EM AMBIENTE DIGITAL: UMA EXPERIÊNCIA NA FACULDADE DE ARQUITETURA DA UNIVERSIDADE FEDERAL DA BAHIA
}

\author{
TEACHING OF ARCHITECTURAL DESIGN IN DIGITAL \\ ENVIRONMENT: AN EXPERIENCE AT THE DEPARTMENT \\ OF ARCHITECTURE AT FEDERAL UNIVERSITY OF BAHIA
}

\author{
Sérgio Dias Maciel ${ }^{1,2}$, Arivaldo Leão de Amorim², Érica de Sousa Checcucci
}

RESUMO: Este trabalho apresenta e discute a experiência vivenciada na disciplina ARQ016 - Ateliê I, ofertada para alunos ingressantes do curso de graduação em Arquitetura e Urbanismo da Universidade Federal da Bahia durante o ano letivo de 2016. A proposta pedagógica desenvolvida partiu do pressuposto de que a plena utilização dos recursos computacionais desde o início do curso pode oferecer melhores resultados de aprendizagem, desde que aplicados de forma adequada, do que o simples uso dos recursos tradicionais de desenho. O método empregado teve como foco os seguintes aspectos: reduzido número de aulas expositivas e apresentação gradual do conteúdo programático; pesquisa orientada sobre as atividades projetuais; realização de vários exercícios de complexidade crescente; concepção projetual por meio de croquis e modelagem geométrica; apresentação e discussão dos exercícios através de seminários, com participação dos alunos e orientações coletivas, e, por fim, confecção de pranchas técnicas em nível de estudo preliminar. Todas as atividades foram realizadas com a ampla utilização dos recursos computacionais como principal ferramenta de apoio, seja para as pesquisas de referências, a concepção e o desenvolvimento da solução, seja ainda para a representação gráfica da proposta projetual. Os resultados obtidos foram considerados muito significativos e puderam refletir o desenvolvimento, amadurecimento e a autonomia dos alunos frente às atividades solicitadas e a organização dos conhecimentos necessários.

PALAVRAS-CHAVE: Ensino de Projeto; Projeto em Ambiente Digital; Projeto de Arquitetura; CAD.

ABSTRACT: This paper presents and discusses the experience of ARQ 016 - Ateliê I, a discipline offered to incoming students of the graduation course on Architecture and Urbanism of University of Bahia during the academic year of 2016. The developed pedagogical proposal assumed that a comprehensive utilization of computing resources since the beginning of the course, if properly applied, can offer better learning results than the simple use of traditional drawing resources. The focuses of this method were: reduced number of lectures and gradual presentation of the program content; oriented research on project activities; realization of several exercises with increasing complexity; project design through sketches and geometric modeling; presentation and discussion of exercises through seminars, with great participation of students and collective guidelines, and, finally, preparation of technical boards at preliminary study level. All activities were carried out with a wide use of computer as the main support tool, either for references researches, design and development of the design proposal, or for its graphic representation. The results were considered very significant and could reflect the development, maturation and autonomy of the students, in face of the activities requested and the organization of the necessary knowledge.

KEYWORDS: Design Teaching; Design in Digital Environment; Architectural Design; CAD.

\footnotetext{
How to cite this article:

MACIEL, S. D.; AMORIM, A. L.; CHECCUCCI, E. S. Ensino de projeto de arquitetura em ambiente digital: uma experiência na Faculdade de Arquitetura da Universidade Federal da Bahia. Gestão e Tecnologia de Projetos, São Carlos, v. 13, n. 1 p. 21-38, 2018. http://dx.doi.org/10.11606/gtp.v13i1.133839
}

Fonte de financiamento: O primeiro autor teve 0 apoio de uma bolsa de doutorado concedida pela Fundação de Amparo à Pesquisa do Estado de Mato Grosso (Fapemat)

Conflito de interesse: Declaram não haver

Submetido em: 21/06/2017 Aceito em: 08/01/2018 


\section{INTRODUÇÃO}

As dificuldades encontradas no ensino de projeto de arquitetura descritas por Silva (2003, 2007), Janot (2003), Carsalade (2003), Malard (2005), Vargas (2005), entre outros, são recorrentes por motivos diversos, como a subjetividade na análise e avaliação de projetos, a manutenção de hierarquia em sala de aula entre "mestres x aprendizes" e a utilização de dicotomias como a "forma segue a função" ou "menos é mais". Mas, se por um lado há o reconhecimento sobre as dificuldades, por outro há também diversos autores - como Kowaltowski et al. (2000), Celani (2007), Nardelli (2007) e Florio (2011) - que sinalizam uma transformação no ensino de projeto por meio da utilização mais incisiva de recursos computacionais, disponíveis como apoio nas atividades projetuais.

Essa discussão também está presente em Kolarevic (2003), ao afirmar que uma nova expressão de arquitetura teria nascido com a revolução causada pela utilização do computador em novos métodos de projeto, incorporando informações especialmente com relação ao desempenho estrutural, acústico, de conforto ambiental, e de geração e transformação das formas. Oxman (2008) afirma que, em uma primeira etapa, o computador apenas substituiu a prancheta de desenho, passando o desenho manual para o digital. Entretanto, nas etapas subsequentes, apresentou-se um desenvolvimento crescente de recursos tanto no acúmulo de informações quanto na utilização de ferramentas para a concepção arquitetônica, incorporando conhecimentos específicos e interdisciplinares, muitas vezes associados e empregados de modo original.

Segundo Florio, as transformações causadas na arquitetura pela inserção dos recursos computacionais ainda são incipientes no Brasil, e não conseguiram transformar nem mesmo o ensino de graduação, que continua defasado:

as novas tecnologias digitais potencializaram a criação de projetos de arquitetura. Desde a década de 1990 houve grandes avanços na modelagem geométrica, na modelagem paramétrica, na prototipagem rápida, nos recursos de simulação, animação e de fabricação digital. Contudo, o ensino de projeto pouco se alterou diante destas rápidas transformações tecnológicas, aumentando a defasagem entre a realidade e a universidade. [...] Simulações de ambientes, de conforto térmico e acústico, de comportamento estrutural e deformações ainda são praticamente desconhecidos nas faculdades de arquitetura (FLORIO, 2013, p. 56).

Diante desse panorama, é necessário que se faça uma melhor análise sobre as potencialidades dos recursos computacionais, que podem oferecer ao aluno de arquitetura, já nas primeiras atividades projetuais, a ampliação do entendimento e da percepção que envolvem a concepção do projeto e, assim, obter mais informações diante da precisão dos dados e da melhor visualização dos modelos gerados.

Dessa forma, o objetivo principal deste artigo é apresentar uma experiência sobre a utilização do computador como suporte ao desenvolvimento da projetação arquitetônica no ensino de graduação, em uma turma ingressante (Ateliê I, Universidade Federal da Bahia - UFBA), desmistificando a ideia de que seu uso é um agente limitador dos processos de criação e um entrave ao aprendizado de projeto, especialmente nas séries iniciais do curso de Arquitetura.

A pesquisa foi fundamentada no método experimental que, segundo Serra (2006, p. 77-78), baseia-se na realização de experimentos planejados "em ambiente controlado, visando a realizar as observações que conduzirão a conclusão", a partir de execução de exercícios de projetação, utilizando recursos de computador. 
Ainda segundo Serra (2006), a pesquisa também possui aspectos de estudo de caso, uma vez que procura investigar o desenvolvimento acadêmico da turma dessa disciplina a partir de análises qualitativas sobre o resultado das atividades solicitadas que, no caso, corresponderam a diversas atividades realizadas no ano letivo de 2016, como oficinas, seminários e atividades de projetação.

\section{EXPERIMENTOS DIDÁTICOS EM AMBIENTE DIGITAL}

Atividades didáticas que envolvem o uso dos recursos computacionais no ensino de arquitetura e urbanismo são normalmente desenvolvidas com dois objetivos: (1) o aprendizado de softwares para utilização direta nas disciplinas de projeto de arquitetura, como é o caso das disciplinas de informática aplicada à arquitetura, especialmente na construção do modelo ${ }^{1}$ da edificação e no desenho de representação, ou (2) a exploração, através de ensaios, da concepção da forma, por meio de modeladores geométricos ${ }^{2}$ ou ferramentas de auxílio ao projeto de formas complexas, como algoritmos, por exemplo.

Nessas duas situações, as atividades foram se especializando em complexidade à medida que os softwares foram evoluindo. Segundo Eastman (1999), ao longo dos anos, as ferramentas CAD (Computer Aided Design) estiveram sob três paradigmas distintos:

- ferramentas para edição de geometria voltadas para a representação do desenho técnico ou da modelagem geométrica do objeto em projeto;

- ferramentas para aplicações específicas para o dimensionamento de componentes da edificação ou para a simulação numérica;

- ferramentas para representação do modelo da edificação e suas informações, capazes de acumular informações de várias áreas específicas em um modelo único.

Em 1992, Andrade, Amorim e Pereira (1994) descrevem uma primeira experiência realizada na Faculdade de Arquitetura da Universidade Federal da Bahia (FAUFBA) com a disciplina Computação Gráfica Aplicada à Arquitetura I, integrada à disciplina de projeto (Planejamento III), em que se utilizou o software AutoCAD ${ }^{3}$.

No Brasil, até o final da década de 1990, as atividades no ensino envolvendo o uso de computadores para projeto eram predominantemente desenvolvidas com o AutoCAD, até então a ferramenta mais utilizada. Seu uso objetivava a modelagem e manipulação de formas geométricas para a composição e representação de projetos arquitetônicos, conforme experimentos descritos por Farrag, Braga e Teixeira (2000).

Destaca-se que os processos de projeto que envolvem manipulação de formas geométricas e utilização de referências e analogias são apresentados por Broadbent (1973), Rowe (1987), Mitchell (2010) e Lawson (2011) como mecanismos usuais de arquitetos para a projetação arquitetônica, realizados diretamente sobre os modelos criados.

Posteriormente, em experimentos descritos por Silva et al. (2012), o objetivo era a reprodução de modelos arquitetônicos de referência em ambiente digital, a fim de explorar, com o software SketchUp ${ }^{4}$, especialmente a utilização de curvas e superfícies complexas no ato de modelagem. Em

Este é o modelo geométrico, que representa um projeto de arquitetura no computador em três dimensões. Modeladores geométricos são ferramentas usadas para a representação da forma dos objetos tridimensionais no computador.

Software da empresa Autodesk. Disponível em: <https://goo.gl/8jpW5A>. Acesso em: 18 jan. 2018

Software da empresa Trimble. Disponível em: <https://goo.gl/PKPDpR>. Acesso em: 19 jan. 2018. 
abordagens mais recentes, Florio (2011) e Tramontano (2015) apresentam experimentos didáticos utilizando o software Rhinoceros ${ }^{5}$ com o plugin Grasshopper 6 , que podem envolver a modelagem de formas complexas por meio da utilização de algoritmos, em contraposição à construção interativa direta do modelo geométrico.

No entanto, ao longo dos anos, pôde-se observar que a utilização dos recursos computacionais sempre ocorreu em turmas adiantadas, próximas da metade do curso ou de alunos concluintes e também em disciplinas adjacentes às de projeto, como descrito nos experimentos de Andrade, Amorim e Pereira (1994), Farrag, Braga e Teixeira (2000), Silva et al. (2012), Florio (2011) e Tramontano (2015). Assim, verifica-se que a utilização de recursos computacionais para apoio às atividades projetuais não ocorre com frequência em turmas iniciais de projeto, embora sejam amplamente difundidas suas vantagens e seu potencial didático.

Assim, a partir de suas experiências de vários anos no ensino de projeto e de informática aplicada, os autores, vislumbrando as potencialidades encontradas nos recursos computacionais para o ensino de projeto, propuseram na FAUFBA, em 2016, a uma turma da disciplina Ateliê I (Projeto de Arquitetura) para alunos ingressantes no curso de Graduação em Arquitetura e Urbanismo, uma metodologia que prevê ampla utilização do computador como suporte a todas as atividades da disciplina.

\section{O ATELIÊ I: PRESSUPOSTOS E METODOLOGIA}

A disciplina Ateliê I (Projeto de Arquitetura) na Faculdade de Arquitetura da Universidade Federal da Bahia é anual, possui carga horária de 12 horas semanais (total de 408 horas), e está presente no primeiro ano da matriz curricular do curso de graduação em Arquitetura e Urbanismo. Ao todo, são oferecidas oito turmas da disciplina, com 15 alunos cada para atender ao ingresso anual de 120 alunos. As turmas são agrupadas de duas em duas, resultando na prática em quatro turmas de 30 alunos, sob responsabilidade de dois docentes por agrupamento.

A disciplina tem como objetivos: (1) estimular a criatividade e o desenvolvimento da percepção espacial; (2) introduzir os métodos de projeto arquitetônico e urbano; e (3) capacitar em métodos e técnicas para criação, desenvolvimento, avaliação, otimização e representação da solução projetual. Normalmente as aulas sobre representação gráfica de arquitetura apresentam conteúdos de desenho técnico arquitetônico, e são trabalhadas em um ambiente com recursos tradicionais, como o uso de pranchetas e instrumental convencional, e a confecção de desenhos a lápis sobre papel manteiga.

Tendo em vista as dificuldades nas relações de ensino-aprendizagem a partir das limitações pedagógicas decorrentes do processo usual oferecido pelas instituições de ensino, e diante de um quadro pouco favorável a mudanças, em 2016 foi proposta uma versão da disciplina Ateliê I para duas turmas (T01/P01 e T02/P02) de alunos ingressantes, com metodologia diferenciada das demais turmas oferecidas naquele ano.

Dessa forma, a metodologia empregada para a nova turma foi planejada com sua estrutura pedagógica pautada em três abordagens fundamentais: (1) realização de pesquisas de referências, pelos alunos, para cada atividade proposta; (2) apresentações de todas as atividades em seminários, com promoção de discussões coletivas e orientações; e (3) utilização do computador como principal recurso de apoio, seja para pesquisas on-line em sala de aula, para modelagem geométrica das propostas projetuais e confecção das pranchas de desenho, seja, ainda, para a organização e

Software da empresa Robert McNeel \& Associates. Disponível em: <https://goo.gl/NwqWVz>. Acesso em: 19 jan. 2018.

Plugin para o software Rhinoceros. Disponível em: <https://goo.gl/uPXiRX>. Acesso em: 19 jan. 2018. 
exposição do material produzido para os seminários de apresentação e discussão dos projetos.

As aulas foram realizadas no Laboratório de Estudos Avançados em Cidade, Arquitetura e Tecnologias Digitais (LCAD), que dispõe de três salas com 35 computadores para atividades de ensino e pesquisa, além de dois projetores multimídia. A disciplina contou com a participação de 3 professores (sendo um deles em estágio docente) e 3 alunos monitores, em regime de revezamento.

O curso foi planejado de modo que todas as atividades pudessem ser realizadas na instituição durante as doze horas de aulas semanais. Toda solicitação e explicação das atividades foi feita em sala de aula, com a respectiva documentação postada no ambiente virtual de ensino-aprendizagem (Moodle) da instituição através de editais, especificando as atividades e os produtos a serem entregues, bem como seus respectivos cronogramas.

Como parte da estratégia metodológica, a forma de apresentação dos conteúdos didáticos dos diversos assuntos - desenho técnico, estrutura, escadas, rampas e elevadores, elementos de cobertura, entre outros - utilizouse de linguagem técnica precisa, mas acessível a alunos do primeiro ano. Para cada tema, no contexto relativo às atividades, a complexidade foi crescente e os refinamentos, sucessivos, de modo a focar conteúdo e discussão de forma aplicada e produtiva. Com isso, procurou-se assegurar o pleno entendimento dos alunos em relação às tarefas a serem realizadas, a fim de estas sempre constituírem um desafio dentro de suas capacidades de realização.

Antes de iniciar as atividades projetuais, foram ministradas aulas sobre arquitetura e temas correlatos, como introdução à projetação arquitetônica e seus aspectos principais: ergonomia, conforto térmico e estrutura. Como apoio metodológico, foram apresentadas ferramentas específicas para uma iniciação à abordagem projetual - especialmente na construção do partido arquitetônico ${ }^{7}$, explorado por Neves (1998) -, como diagramas, estudos de insolejamento, ventilação e plano de massas. Também foram apresentados os tipos de restrições ${ }^{8}$ existentes à projetação arquitetônica, conforme Lawson (2011).

Às pesquisas de referência, foram somadas as pesquisas metodológicas do projeto, configurando o programa de necessidades, como restrições internas: pesquisa sobre o pré-dimensionamento dos espaços e relações entre os espaços por meio de diagramas; e como restrições externas: índices para ocupação, aproveitamento, recuos, relevo e contextos urbanos. As pesquisas serviram para acumular informações, sendo necessário que os alunos as organizassem para estabelecer as diretrizes para suas propostas projetuais, segundo suas próprias heurísticas, como sugerem Broadbent (1973) e Rowe (1987), buscando seu gerador primário ${ }^{9}$ e, por conseguinte, sua ideia principal (LAWSON, 2011).

Para auxílio nas atividades de projetação, foram oferecidas oficinas para a produção de mapas mentais (4 horas), para croquis (12 horas), de modelagem (12 horas), entre outras. Como principal recurso para a projetação de arquitetura, foi escolhido o software SketchUp, que oferece uma versão para download gratuito. Tal programa permite a construção do modelo digital, com aplicação de materiais e possui amplos repositórios on-line de modelos de componentes arquitetônicos para utilização, também de uso gratuito. Com o SketchUp, é possível executar cortes e visualizar fachadas e perspectivas automaticamente, além de produzir animações. O software oferece ainda recursos para inserção do modelo em imagens de satélite, visualização de sombras e diversos plugins para automatizar a construção de escadas, coberturas e outros elementos construtivos. Através da versão professional, existente em algumas máquinas do LCAD, foi

Partido arquitetônico é a síntese da combinação entre as informações do tema, das restrições e das ideias geradoras do projeto.

As restrições referem-se às limitações impostas para o projeto e podem ter várias origens: podem ser causadas pelos clientes, pelo órgão público ou mesmo pelo arquiteto.

O gerador primário é a ideia inicial que conduz decisões projetuais. 
possível, também, o uso dos seguintes recursos: ambiente para ilustração, importação automática de cenas geradas a partir do modelo para a construção das pranchas de desenho (layout) e criação de estilos de linhas, para uma apresentação personalizada (style builder).

Devido à maioria das máquinas no LCAD conter apenas a versão gratuita do SketchUp, foram utilizados outros dois softwares, apresentados durante a oficina de modelagem: um editor de PDF, o CutePDF ${ }^{10}$, para gerar desenhos neste formato com escala; e o Inkscape ${ }^{11}$, para refinar desenhos gerados no Sketchup e diagramá-los em folhas (padrão ABNT).

Para cada atividade de projeto, os alunos apresentaram suas propostas projetuais em seminário, com pesquisas de referência sobre o tema, requisitos e restrições, funcionograma e fluxograma, estudos de insolejamento e de ventilação, estudo de massa e principais materiais de construção utilizados. Após os seminários, os alunos dispunham de certo tempo para incorporar ou adequar suas propostas às principais críticas e sugestões recebidas. Posteriormente, os projetos foram desenvolvidos em formato de pranchas técnicas para a impressão e entrega para correção final e atribuição das notas.

Ao longo do semestre letivo 2016.2, foi implantada uma apresentação preliminar, individual, antes do seminário, para acompanhamento mais próximo, o que diminuiu possíveis falhas, seja com relação à pesquisa ou à solução proposta, sempre com o objetivo de orientar e corrigir, promovendo a reduzindo de equívocos e produzindo apresentações mais objetivas e de melhor qualidade. Nos últimos exercícios, além do seminário e das pranchas técnicas, foi solicitada, também, a produção de vídeos para apresentação do projeto.

O Quadro 1 apresenta de forma resumida o conjunto das atividades realizadas ao longo dos períodos letivos 2016.1 e 2016.2 das turmas 1 e 2 de Ateliê I.

Quadro 1: Atividades didáticas do Ateliê 1

\begin{tabular}{|l|l|}
\hline \multicolumn{1}{|c|}{ ATIVIDADES } & \multicolumn{1}{c|}{ ATIVIDADES DO PERÍODo: 2016.1 } \\
\hline Introdução & $\begin{array}{l}\text { Discussão: O que é arquitetura? O que é cidade? O que é } \\
\text { projeto? Por que fazer o projeto? Projetação arquitetônica. }\end{array}$ \\
\hline $\begin{array}{l}\text { Mapas mentais e mapas } \\
\text { conceituais }\end{array}$ & $\begin{array}{l}\text { Exercícios de mapas mental e conceitual sobre projeto de } \\
\text { arquitetura. }\end{array}$ \\
\hline Desenho de observação & $\begin{array}{l}\text { Escolher e representar à mão livre dez cenas ou objetos } \\
\text { diferentes, observando conteúdos discutidos em sala de aula. }\end{array}$ \\
\hline $\begin{array}{l}\text { Oficina de modelagem } \\
\text { SketchUp }\end{array}$ & $\begin{array}{l}\text { Construção de modelo geométrico. Escolha de objetos, } \\
\text { medições e modelagem. }\end{array}$ \\
\hline $\begin{array}{l}\text { Visita técnica e } \\
\text { percepção urbana }\end{array}$ & $\begin{array}{l}\text { Vistoria, análise e apresentação de relatório sobre espaço } \\
\text { urbano: Forte de São Diogo até Largo da Mariquita em } \\
\text { Salvador. }\end{array}$ \\
\hline Ergonomia & $\begin{array}{l}\text { Introdução à ergonomia. Análise de um posto de trabalho } \\
\text { residencial: escolher um posto na sua residência e analisar } \\
\text { segundo critérios ergonômicos. }\end{array}$ \\
\hline $\begin{array}{l}\text { Preparação de pranchas } \\
\text { técnicas }\end{array}$ & $\begin{array}{l}\text { Discussão sobre elementos de um projeto arquitetônico e } \\
\text { normas de desenho técnico. }\end{array}$ \\
\hline
\end{tabular}

\footnotetext{
10 CutePDF é um software gratuito para edição de PDF. Disponível em: <https://goo.gl/4ZkbKs>. Acesso em: 19 jan. 2018.

11 Inkscape é um software livre para desenho vetorial. Disponível em: <https://goo.gl/W6LvsG>. Acesso em: 19 jan. 2018.
} 
Quadro 1: Continuação

\begin{tabular}{|c|c|}
\hline ATIVIDADES & ATIVIDADES DO PERÍODO: 2016.1 \\
\hline $\begin{array}{l}\text { Projeto de mobiliário } \\
\text { urbano }\end{array}$ & $\begin{array}{l}\text { 1a atividade de projeto: estudo de equipamento urbano, a ser } \\
\text { implantado no trecho vistoriado na atividade "visita técnica e } \\
\text { percepção urbana". }\end{array}$ \\
\hline Projeto de praça & $\begin{array}{l}\text { 2a atividade de projeto: discussão sobre paisagem urbana. } \\
\text { Pesquisa sobre praças. Análise e reestruturação de praça } \\
\text { escolhida (atividade em grupo). }\end{array}$ \\
\hline Projeto de galpão & $\begin{array}{l}\text { 3a atividade de projeto: pesquisa sobre galpão. Projetar um } \\
\text { galpão segundo pesquisa de interesse para destinação do } \\
\text { espaço. }\end{array}$ \\
\hline $\begin{array}{l}\text { Visita técnica e } \\
\text { percepção urbana; } \\
\text { desenvolvimento de } \\
\text { croquis }\end{array}$ & $\begin{array}{l}\text { Visita à cidade de Cachoeira/BA. Desenho de pelo menos dez } \\
\text { cenas do espaço urbano à mão livre. }\end{array}$ \\
\hline Conforto ambiental & Discussão sobre o tema. \\
\hline $\begin{array}{l}\text { Projeto de residência } \\
\text { térrea }\end{array}$ & $\begin{array}{l}\text { 4a atividade de projeto: pesquisa sobre residências e } \\
\text { arquitetos. Definir o programa e projetar uma residência } \\
\text { térrea. }\end{array}$ \\
\hline TEMA & ATIVIDADES DO PERÍODO: 2016.2 \\
\hline Legislação & $\begin{array}{l}\text { Apresentação e discussão sobre a LOUOS, PDDU e Código } \\
\text { de Obras. }\end{array}$ \\
\hline Projeto centro comercial & $\begin{array}{l}\text { 5a atividade de projeto: pesquisa sobre centros comerciais de } \\
\text { pequeno porte. Definir programa, projetar centro comercial. }\end{array}$ \\
\hline Projeto de pousada & $\begin{array}{l}\text { 6a atividade de projeto: pesquisa sobre pousadas. Projeto de } \\
\text { uma pousada a partir de um dado programa de necessidades } \\
\text { (atividade em dupla). }\end{array}$ \\
\hline Projeto de capela & $\begin{array}{l}\text { 7a atividade de projeto: pesquisar capelas ou templos de } \\
\text { pequeno porte. Definir programa e pré-dimensionamento. } \\
\text { Projeto de capela ou templo de pequeno porte. }\end{array}$ \\
\hline Encerramento do curso & Avaliação geral. \\
\hline
\end{tabular}

Fonte: Elaborado pelos autores, 2016.

As avaliações só foram realizadas com atribuição de nota para as atividades de projeto, sendo que foram atribuídos peso 4 para os seminários de apresentação e peso 6 para a documentação impressa. Para o cálculo da média final do curso, foram definidos os pesos 4 e 6 , para a média do primeiro e do segundo semestre, respectivamente. Para a atribuição das notas dos seminários foram observadas a qualidade dos slides, a comunicação oral, a pesquisa e a organização de informações e a forma com que serviram para orientar a solução. Já para as pranchas impressas do projeto, foram avaliadas a solução da proposta arquitetônica e a qualidade gráfica dos desenhos.

Como recurso estratégico, a utilização do computador trouxe como expectativas:

- realização de pesquisas de referência diretamente no computador;

- velocidade e precisão para a produção de desenhos técnicos a partir do modelo; 
- vantagens quanto à representação gráfica como: uniformidade dos desenhos, utilização de cores, materiais e texturas, e geração automática de perspectivas;

- vantagens com relação à construção do plano de massas, facilitando a construção geométrica do modelo e seu entorno, simulando áreas iluminadas e de sombra, conforme a incidência solar;

- ampliação das possibilidades formais a serem adotadas e melhor compreensão da espacialidade da solução proposta;

- ampliação dos recursos projetuais, com a utilização de outros programas auxiliares.

\section{APRESENTAÇÃO E DISCUSSÃO DE RESULTADOS}

No início do primeiro semestre de 2016, durante as atividades iniciais, foi realizada uma pesquisa (questionário) com os estudantes, com o objetivo de verificar questões diversas como idade, acesso a computadores e conhecimento prévio de informática. Os alunos presentes $(\mathrm{N}=28)$ responderam ao questionário e verificou-se que a maioria deles $(\mathrm{N}=21)$ tinha menos de 20 anos de idade; todos possuíam computador em suas residências; e a maioria $(\mathrm{N}=20)$ declarou ter conhecimento entre razoável e bom em informática. Os softwares mais utilizados pelos alunos são editores de texto $(\mathrm{N}=28)$, planilhas eletrônicas $(\mathrm{N}=24)$, programas para apresentação de slides $(\mathrm{N}=23)$ e editores de imagens $(\mathrm{N}=14)$. Alguns alunos também declararam ter conhecimento em outros softwares, tais como CorelDraw $(\mathrm{N}=2)$, Illustrator $(\mathrm{N}=2)$, AutoCAD $(\mathrm{N}=10)$, Maya $(\mathrm{N}=1)$ e Revit (N=3).

Com relação à utilização do SketchUp, nenhum dos alunos declarou conhecer o software antes das oficinas, mas, depois delas, a maioria o considerou bom ou muito bom ( $\mathrm{N}=24)$, e apenas alguns consideraramno razoável $(\mathrm{N}=4)$. Com relação à metodologia a ser utilizada, com ampla utilização do computador como ferramenta de apoio, a maioria dos alunos compreendeu a proposta $(\mathrm{N}=26)$, apenas um deles afirmou não compreender a proposta, e outro não respondeu. Todos declararam compreender que a utilização do computador pode beneficiar o processo de trabalho, e descreveram que as vantagens mais esperadas eram a otimização do tempo para a execução dos desenhos $(\mathrm{N}=16)$ e a representação e visualização do projeto $(\mathrm{N}=11)$.

Para as atividades de projeto, optou-se por substituir toda a representação técnica tradicional de desenho a lápis pela utilização do computador sendo que todos os desenhos técnicos necessários seriam obtidos por meio de operações a partir do modelo geométrico do objeto projetado, acarretando, dessa forma, uma diminuição do tempo gasto com representação gráfica, deixando um tempo maior para a concepção da solução projetual.

Deve-se salientar que, apesar da ampla utilização do computador como ferramenta de apoio à projetação arquitetônica, os diagramas e os croquis não deixaram de ser utilizados e valorizados durante as atividades, servindo como comunicação entre professor e aluno e entre alunos, nas apresentações preliminares individuais, nas aulas teóricas e também nas avaliações. Assim, a fase inicial da projetação foi trabalhada com recursos diferentes e complementares, e, nela, os alunos realizaram atividades de pesquisa no computador, ao mesmo tempo em que esboçaram os primeiros estudos, com a utilização de diagramas e croquis, para posteriormente desenvolver os modelos. 
A Figura 1 apresenta o processo de projeto de uma aluna, inicialmente com a utilização de um diagrama para o estudo do projeto de residência (4a atividade de projeto), o croqui e a representação final, executada no computador.

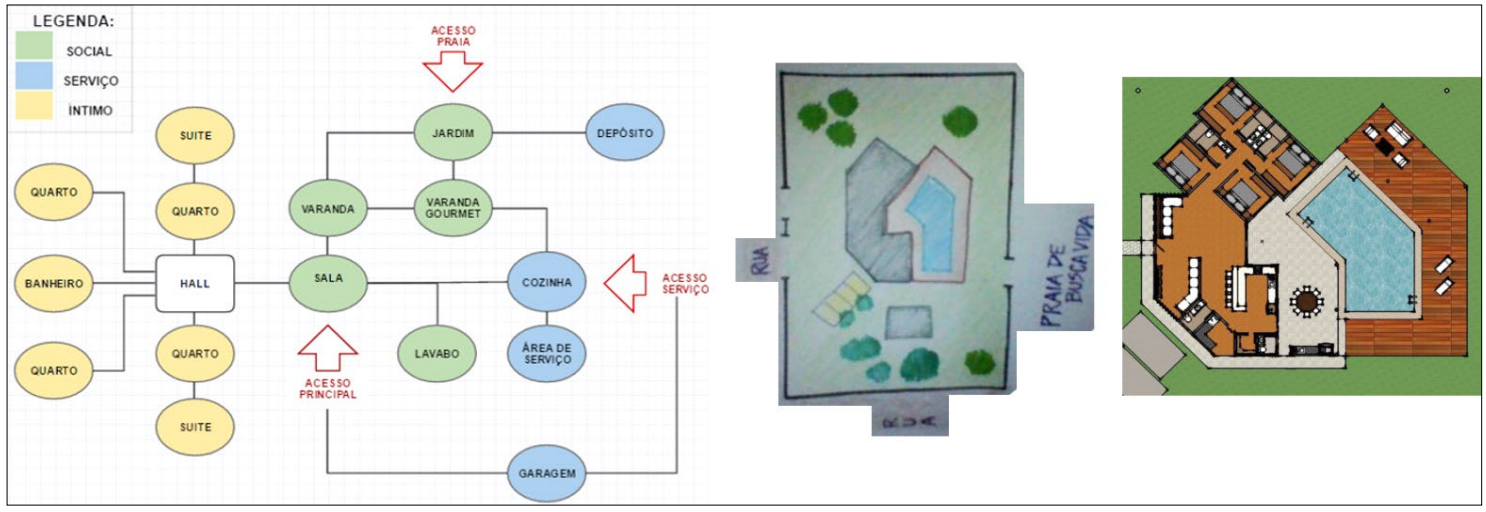

A partir do projeto do centro comercial (5a atividade de projeto), foi reforçado aos alunos que, além da utilização de diagramas e croquis para a consolidação das propostas, eles buscassem uma solução volumétrica inicial, diretamente no computador, consolidando as ideias da construção do partido arquitetônico.

Dessa forma, os projetos tiveram como ponto de partida, juntamente com diagramas e croquis, um estudo volumétrico, evidenciando o partido arquitetônico adotado. A Figura 2 mostra a evolução de um partido arquitetônico, à esquerda, para a proposta consolidada, à direita, já em uma etapa de estudo preliminar.

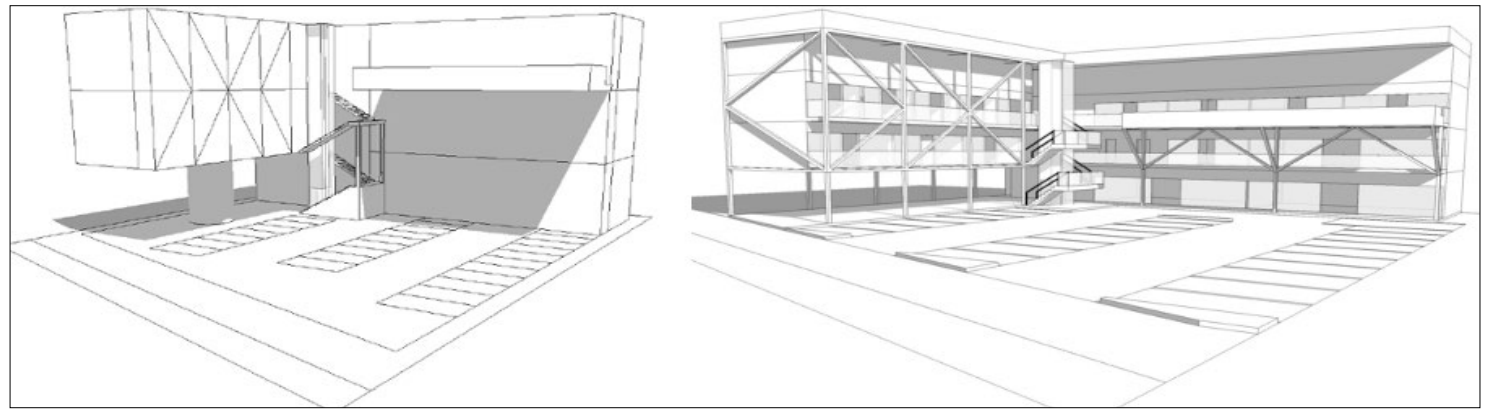

Apesar das vantagens esperadas, a construção das pranchas com desenhos de arquitetura apresentou uma dificuldade inicial, pois a maioria dos alunos utilizou a versão gratuita do SketchUp, houve a necessidade de utilização do CutePDF e do Inkscape, tornando o processo mais trabalhoso. Dessa forma, a construção do modelo e a geração de desenhos (plantas, cortes e fachadas) e perspectivas foram feitas no SketchUp. Posteriormente, foram exportadas em escala pelo editor de PDF, para serem inseridas no Inkscape, onde foram efetuados alguns acabamentos, como as margens das pranchas, desenhos de linhas diferenciadas, textos, legendas, carimbos e hachuras.

No início das atividades de projeto, foram detectados os seguintes problemas, que acarretaram falta de qualidade nos trabalhos: (1) dificuldade, por parte dos alunos, em construir um modelo com geometria precisa; (2) falta de inserção de elementos importantes como esquadrias e equipamentos sanitários; (3) dificuldade no controle de espessura das linhas dos desenhos; e (4) falta de textos explicativos nas pranchas técnicas.
Figura 1: Processo de projeto

Fonte: Trabalho da aluna Gabriela Dantas

Figura 2: Construção do partido arquitetônico

Fonte: Trabalho da aluna lasmine Leal. 
Essas dificuldades foram observadas a partir do projeto de mobiliário urbano (1a atividade de projeto), quando os alunos começaram a projetar no computador e apresentar os desenhos impressos em escala, nas folhas de papel, com a responsabilidade de tornar a proposta projetual compreensível para a leitura técnica. A Figura 3 mostra um exemplo da falta de qualidade na representação gráfica: falta de diferença na espessura das linhas; ausência da representação das esquadrias, ausência de textos indicando os nomes dos ambientes, níveis e áreas; e outros.

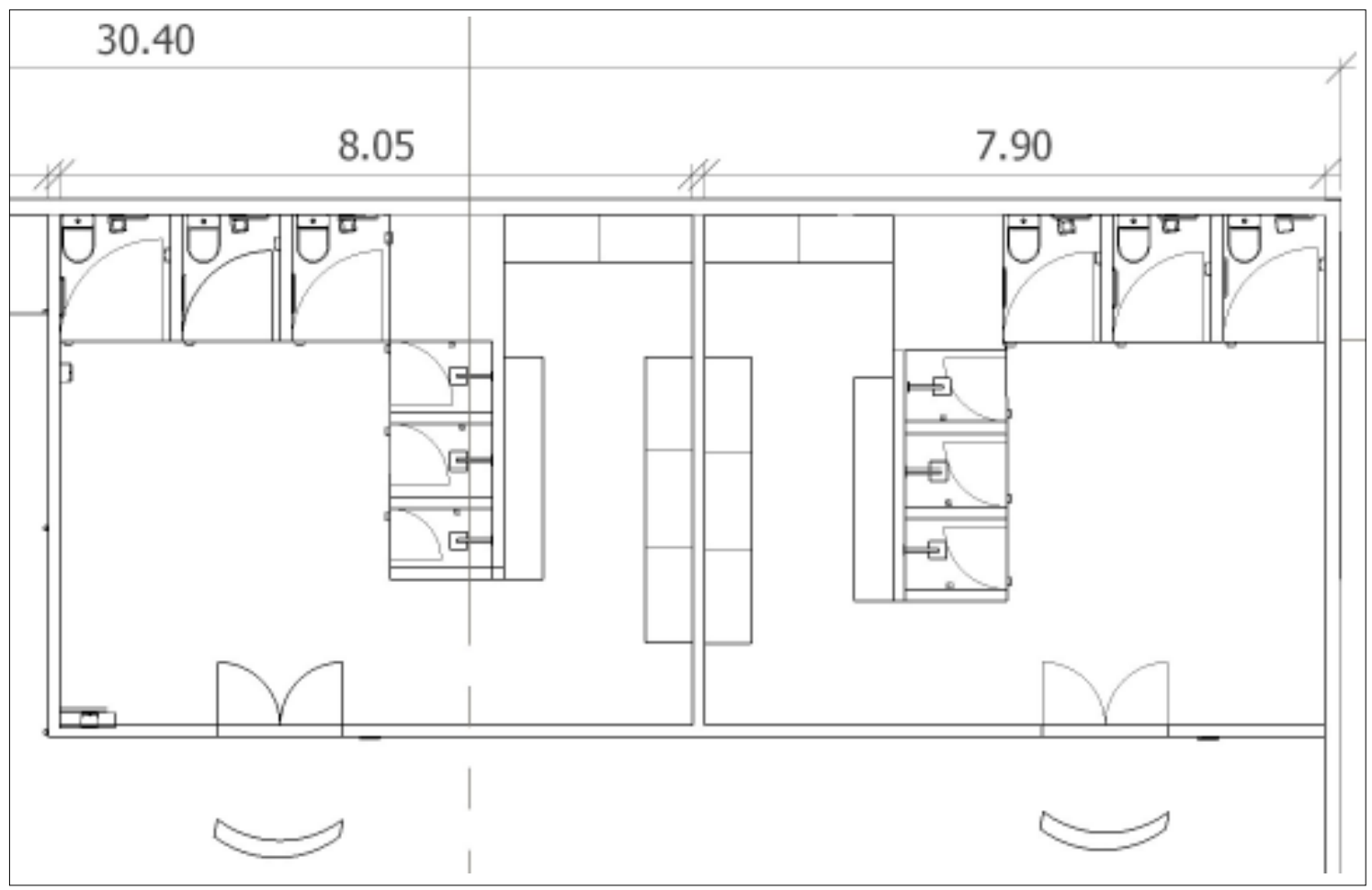

Figura 3: Problemas causados pela falta de qualidade

Fonte: Adaptado pelos autores, 2016.

Figura 4: Problemas com cotas e textos.

Fonte: Adaptado pelos autores, 2016.
Outra dificuldade encontrada com relação à falta de qualidade na representação gráfica, ocorreu no processo de cotagem, muitas vezes com textos de tamanho e posição inadequados, e equívocos em relação à quantidade de casas decimais. A Figura 4 apresenta problemas recorrentes com cotas e textos.

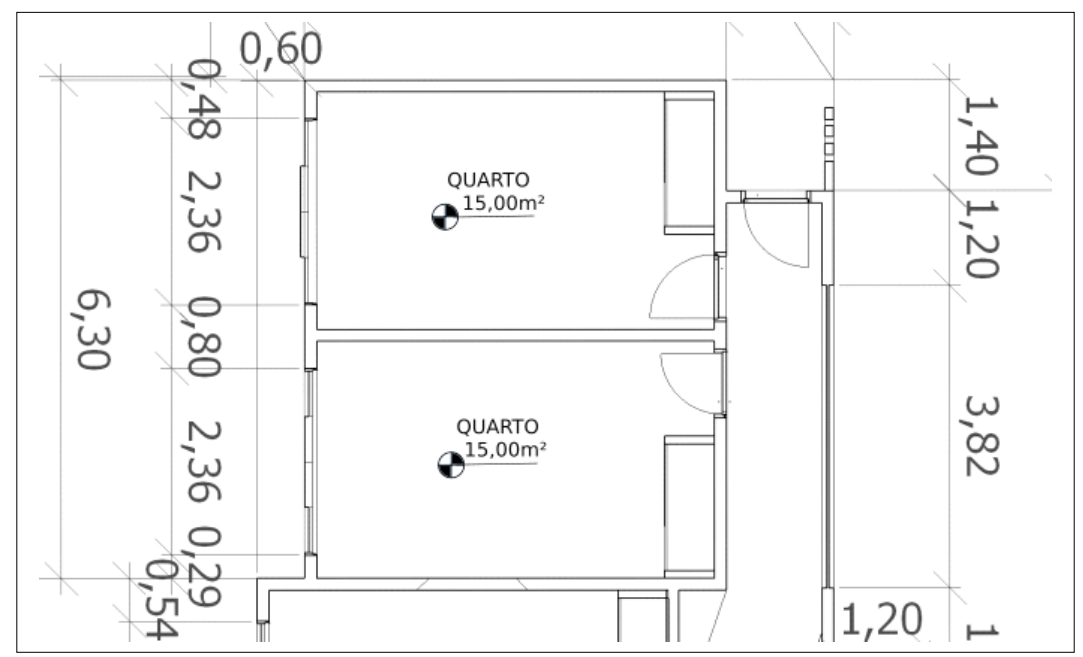


Os problemas de falta de precisão e de qualidade do modelo foram os mais recorrentes, e persistiram até o projeto de residência (4a atividade de projeto), apenas reduzidos nas atividades seguintes. Não foi detectado nenhum problema quanto a dificuldade na concepção do projeto utilizando o computador e, como esperado, também foram apresentados trabalhos com a desejada qualidade gráfica, decorrentes de modelos construídos com precisão geométrica. A Figura 5 apresenta um bom resultado obtido de qualidade gráfica.

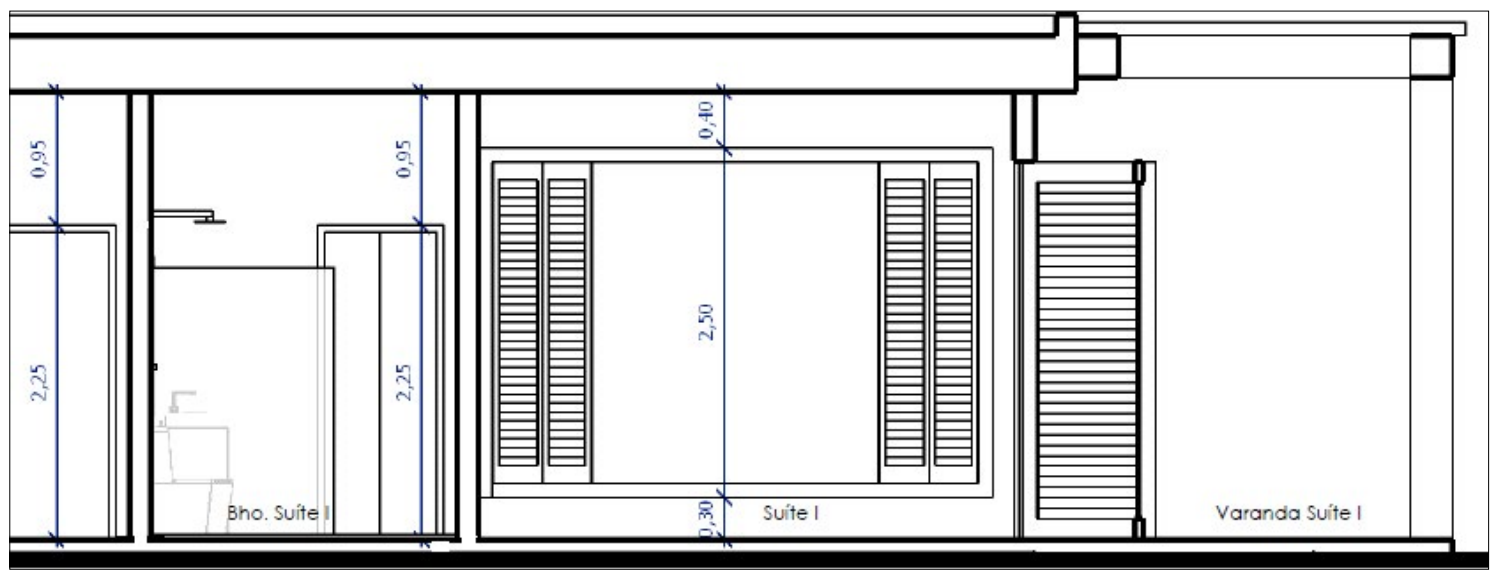

Da mesma forma, a representação gráfica via computador permitiu bons resultados para a visualização do projeto, tanto por meio de imagens estáticas quanto através de animações. A Figura 6 apresenta dois bons resultados que foram valorizados com recursos de sombra projetada e de

Figura 5: Bom resultado da qualidade gráfica

Fonte: Trabalho da aluna Rafaela Tan. aplicação de cor e de texturas:

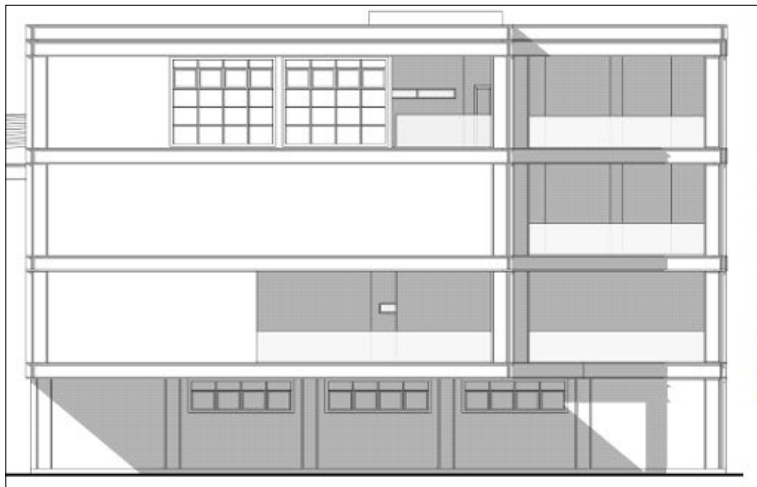

Entender o espaço além do desenho técnico (ou da representação gráfica) é fundamental para o aprendizado. Experimentar formas, materiais e texturas tornam a construção do conhecimento mais rica para o aluno, que pode criar espaços com elementos que possuem identidade com seu universo, e relacionar-se com o espaço projetado, criando seu repertório e compartilhando melhor suas experiências com o professor que, como avaliador, poderá ter uma melhor visão sobre as expectativas dos alunos e, no processo de avaliação, discutir o projeto sobre mais questões, não somente técnicas ou de representação.

A Figura 7 mostra como a identidade do aluno, assim como a do possível usuário do espaço, pode estar presente na construção da proposta. À esquerda, vemos o projeto de galpão (3a atividade de projeto) e, à direita, parte do projeto de pousada (6a atividade de projeto):
Figura 6: Bons resultados gráficos

Fonte: Trabalho dos alunos Rafaela Tan (à esquerda) e Rafael Borges (à direita) 


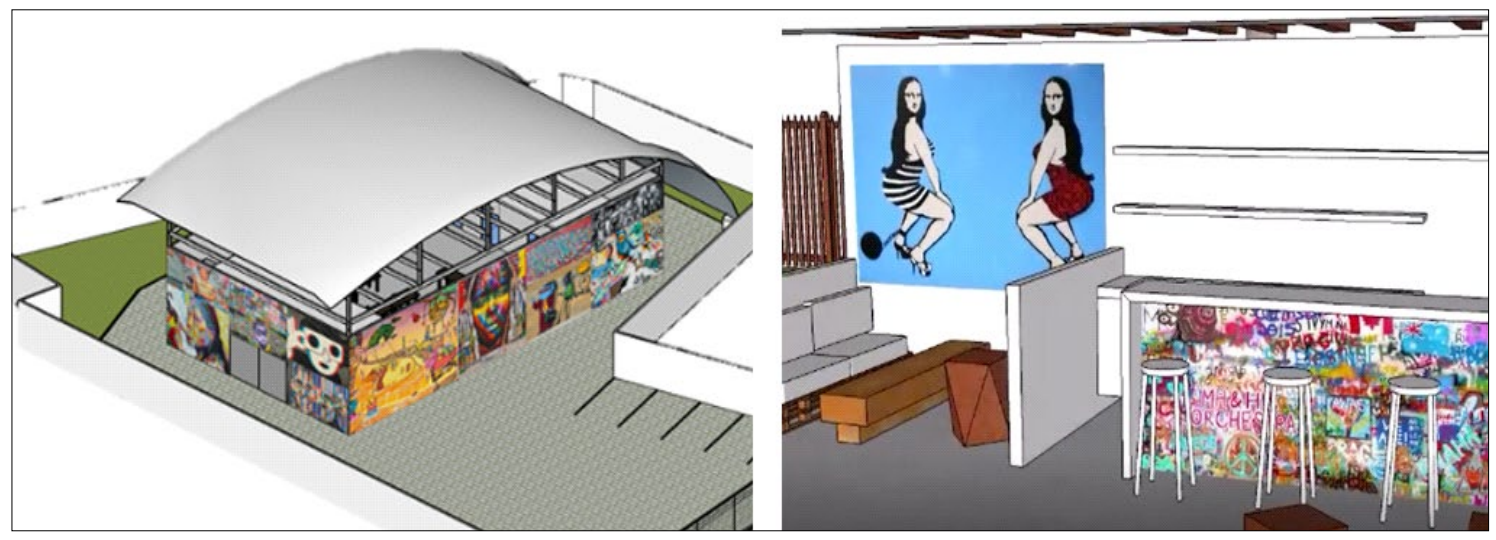

Figura 7: Aspectos da identidade cultural presentes nas propostas

Fonte: Trabalho da aluna Maria Luiza Santana (à esquerda) e das alunas Maria Luiza Santana e Isadora Silva (à direita)
A inserção do modelo em imagens de satélite, adquiridas no próprio software e a importação de arquivos externos ${ }^{12}$ permitiram uma melhor compreensão do projeto, analisando dados do entorno e fatores ambientais, que podem ser decisivos nas soluções projetuais, atuando como fatores restritivos externos. Na Figura 8, é mostrada a implantação da proposta do centro comercial ( 5 a atividade de projeto) no terreno, com os principais edifícios do entorno.

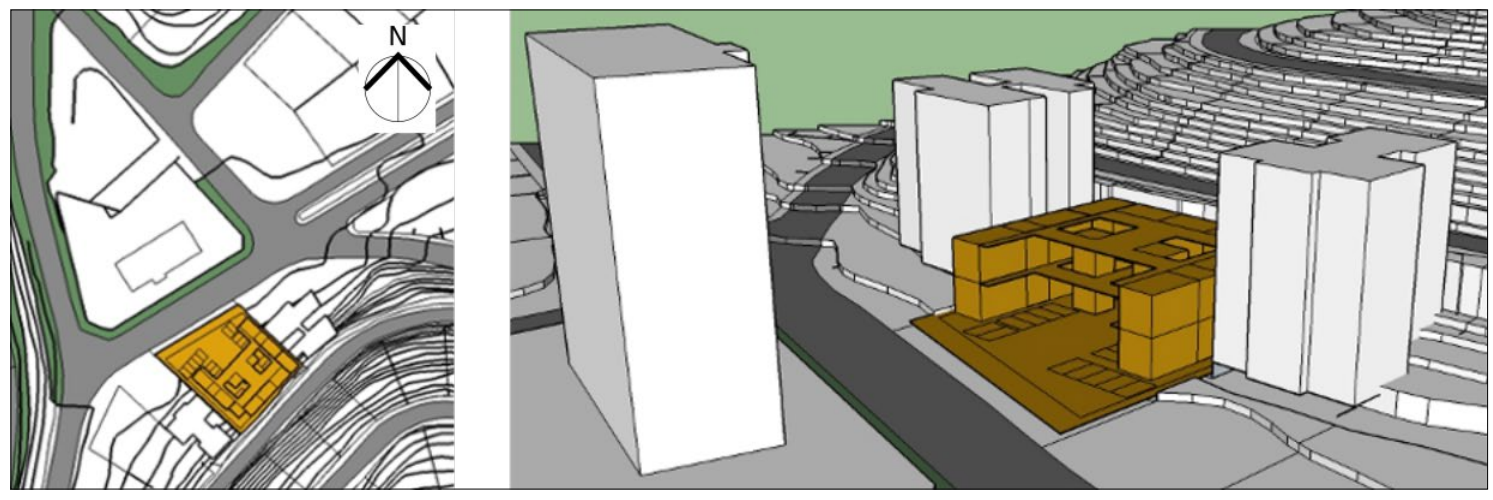

Figura 8: Inserção do modelo em terreno com topografia

Fonte: Trabalho da aluna Maria Luiza Santana

Figura 9: Estudo de insolejamento do modelo

Fonte: Trabalho da aluna Maria Luiza Santana
Na Figura 9, é apresentado um estudo sobre a incidência do sol e as sombras projetadas para o mês de janeiro, às $9 \mathrm{~h}$, à esquerda, e às $15 \mathrm{~h}$, à direita.

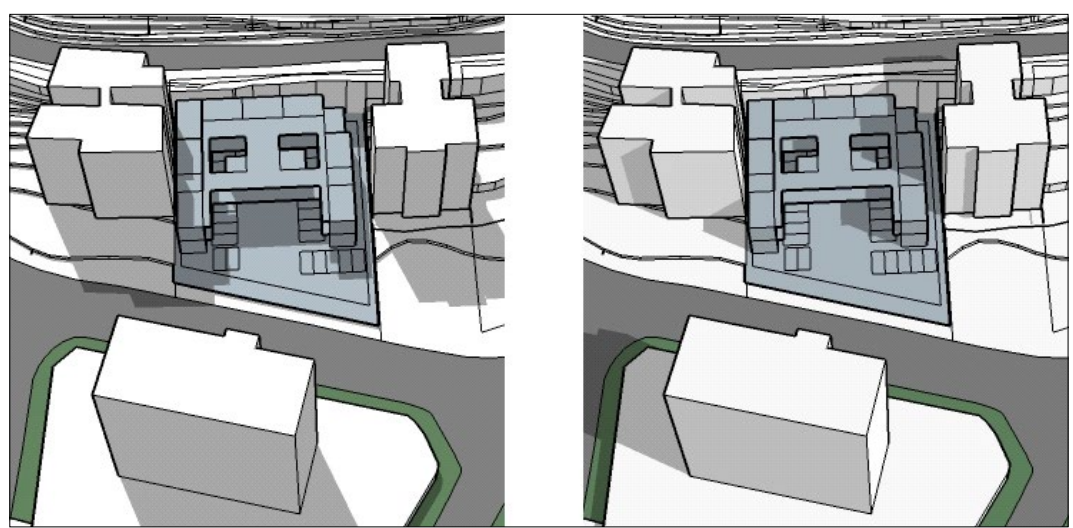

$\overline{12}$ No caso, utilizando o banco de dados da prefeitura de Salvador, para aquisição da topografia do terreno para a atividade de projeto em arquivo formato DWG. 
Pode-se destacar o pensamento completo sobre o projeto, ampliando a visão dos alunos sobre as possibilidades formais e uma melhor compreensão estrutural, evidenciando a espacialidade da proposta. A Figura 10 mostra como a concepção estrutural pode ser melhor entendida e explicitada na construção do modelo geométrico, resultando numa experiência significativa para o aluno. Vale ressaltar que esses alunos, por serem do primeiro semestre, ainda não haviam cursado nenhuma disciplina específica sobre sistemas estruturais, logo, o resultado apresentado no projeto foi obtido a partir de percepções nas suas pesquisas e de discussões sobre o tema em sala de aula.

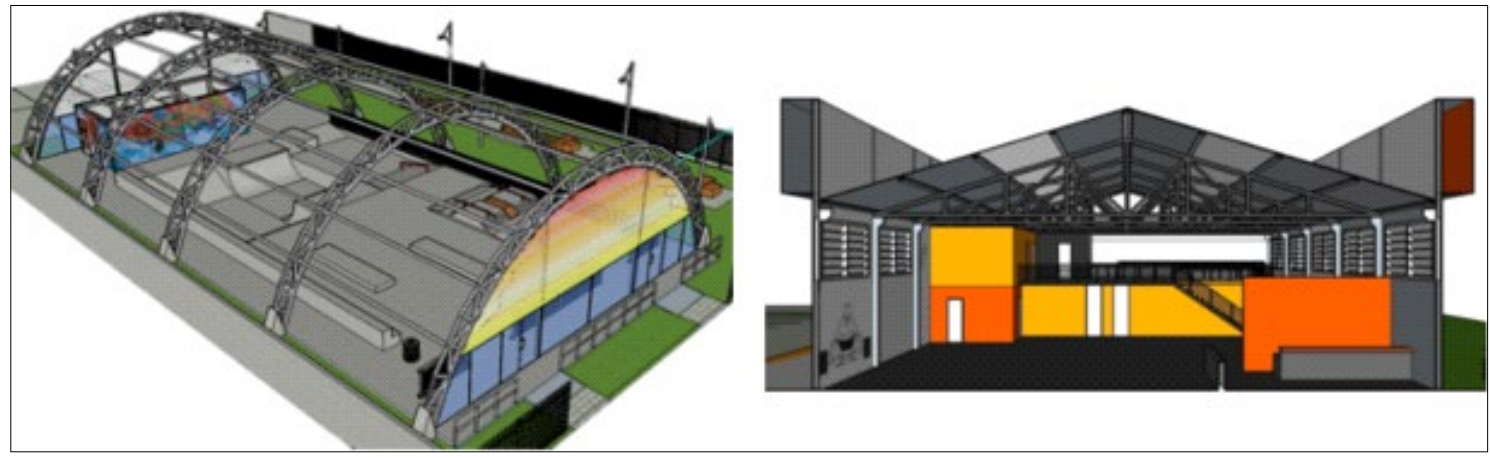

A necessidade de construir formas complexas mostrou uma limitação do software SketchUp na modelagem de formas curvas, conforme a Figura 11, referente ao projeto de mobiliário urbano (1a atividade de projeto). Para a modelagem da cobertura, a aluna contou com a ajuda de um aluno monitor, que a auxiliou, a partir do croqui, utilizando o software Rhinoceros, também disponível no LCAD.

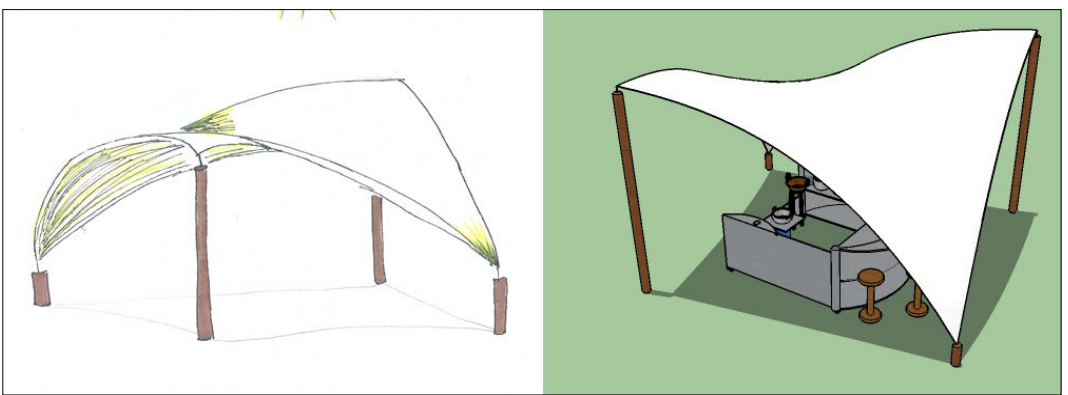

A curiosidade pelo assunto e o interesse pela utilização de novas ferramentas serviram como motivação para que os professores da disciplina Ateliê I promovessem um "curso introdutório"13 sobre modelagem de formas complexas, utilizando o software Rhinoceros.

A última atividade do ano, o projeto de capela (7a atividade de projeto) teve como principal solicitação que os alunos priorizassem a forma como característica de destaque do projeto, tendo o partido arquitetônico trabalhado desde o início do processo. O programa de necessidades fornecido pôde ser alterado para adequar-se às necessidades de cada religião, de modo que fosse possível, caso houvesse interesse, a pesquisa sobre uma religião específica.

Um dos objetivos do exercício seria a investigação do processo de criação da forma com os recursos computacionais e seus desdobramentos, como a necessidade de utilização de outros softwares e seus respectivos processos
Figura 10: Concepção espacial e estrutural da proposta

Fonte: Trabalho das alunas Adaildes Nascimento (à esquerda) e Rafaela Tan (à direita)

Figura 11: Estudo da forma e modelagem

Fonte: Trabalho da aluna Maria Luiza Santana

O curso, gratuito, foi realizado no recesso entre os semestres 2016.1 e 2016.2 e aberto à comunidade acadêmica, sendo que quinze alunos da turma Ateliê I participaram. O curso teve como objetivo principal a introdução de modelagem de formas complexas no Rhinoceros e a utilização do plugin Grasshopper, para modelagem paramétrica, e do plugin Ladybug, para análise ambiental. 
de modelagem. Como esperado, os trabalhos foram apresentados com diferentes soluções formais, seguindo as referências pesquisadas.

A utilização de sólidos geométricos primitivos foram soluções bastante procuradas, conforme descrito por Mitchell (2010) e Lawson (2011). A Figura 12 apresenta algumas soluções projetuais que buscaram referências com utilização em sólidos geométricos.

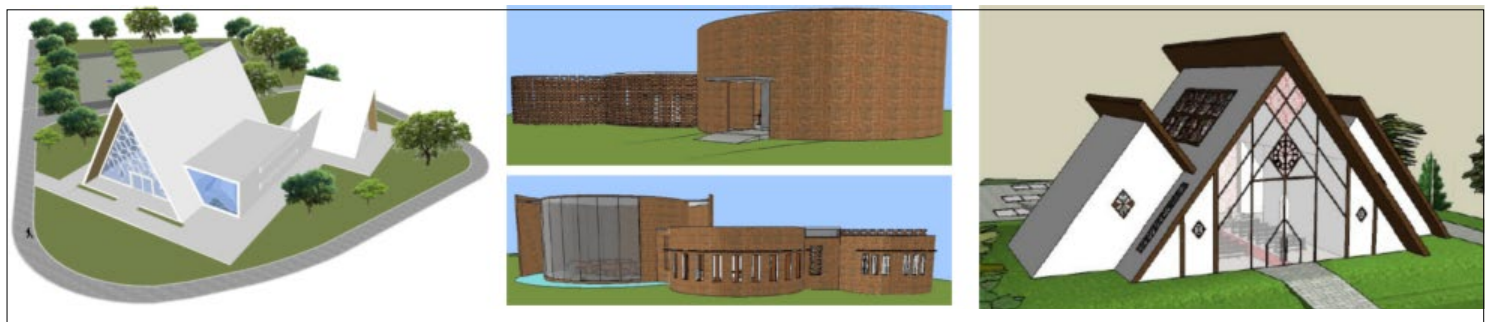

Figura 12: Utilização de sólidos geométricos na composição arquitetônica

Fonte: Trabalho da aluna Rafaela Tan (à esquerda), Júlia Veras (centro) e Beatrice Santiago (à direita).
Além das formas utilizando sólidos geométricos, também foram observados partidos arquitetônicos com composição de planos e superfícies curvas. A Figura 13 apresenta outro conjunto de soluções apresentadas.

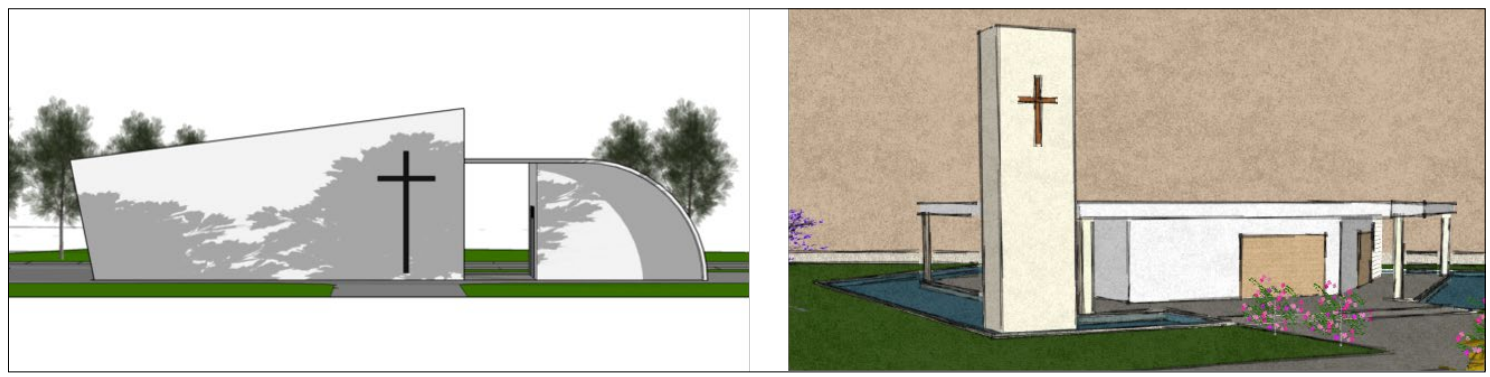

Figura 13: Formas

diferenciadas na composição arquitetônica

Fonte: Trabalhos do aluno André Batista (à esquerda) e da aluna Nicole Figueiredo (à direita)
Também foram expostas soluções em que o partido arquitetônico adotado é similar às tipologias tradicionais. A Figura 14 apresenta trabalhos em que as alunas desenvolveram suas propostas empregando formas convencionais.

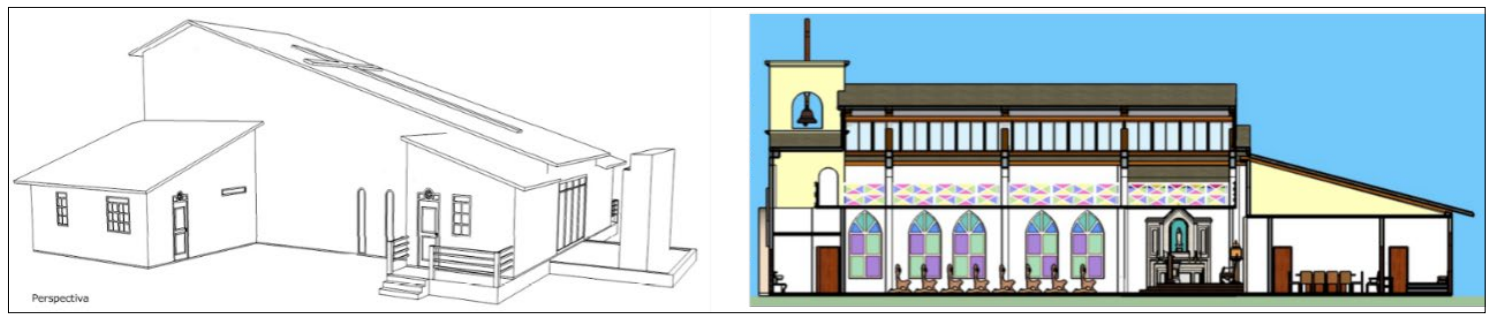

Figura 14: Adoção de partido arquitetônico tradicional

Fonte: Trabalho das alunas Alika Áquila (à esquerda) e Ângela Alvares (à direita).
Apesar de a maioria dos trabalhos terem sido feitos no SketchUp, alguns alunos precisaram recorrer a outros softwares para modelagem de superfícies mais complexas. A Figura 15 apresenta trabalhos em que se utilizaram diferentes recursos, como a ferramenta Edge Surface do AutoCAD, utilizada para a solução da cobertura, uma superfície tipo "paraboloide hiperbólico" (à esquerda), e a ferramenta Edge Curves do Rhinoceros, utilizada para desenvolver o partido arquitetônico da solução (à direita). 


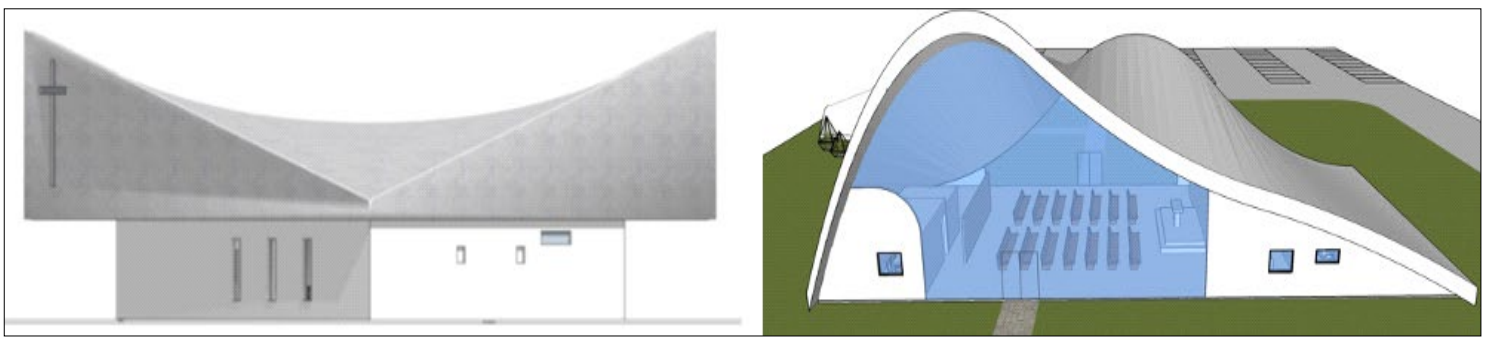

\section{CONCLUSÃO}

Com os resultados apresentados ao final do ano letivo, verificou-se a evolução e o amadurecimento dos alunos, esperado pelos professores. A utilização do ambiente computacional como recurso de apoio permitiu que o projeto atingisse resultados mais expressivos e completos do que quando se utiliza apenas papel e lápis. É fato que uma das dificuldades do ensino de arquitetura é fazer com que o aluno aprenda a pensar o projeto como espaço proposto, além das linhas desenhadas. Com a utilização do computador, a construção dos modelos não serviu apenas para a geração dos desenhos técnicos e a criação de perspectivas, mas para que fossem inseridos ali diversos elementos de expressão individual, por meio de escolha dos materiais de construção da composição da identidade do espaço, o que notadamente foi percebido como um prazer especial desenvolvido pelos alunos em cada atividade.

Ao analisar o desenvolvimento das atividades ao longo do ano de 2016, pode-se verificar que todos os alunos concluintes da disciplina puderam se conscientizar de que o projeto possui um contexto local estabelecido pelo entorno, com edificações próximas e seus usos, e também por um contexto ambiental, que envolve questões de insolação, valorizando áreas de sol e de sombra, e de ventilação, além de como esses contextos devem interferir na tomada de decisões do projeto. Nesses casos, o uso do computador favoreceu o entendimento dessas questões devido à utilização de ferramentas diversas.

Como esperado, a utilização do computador permitiu que houvesse uma dinamização das atividades de projeto, o que pode ser verificado pelo número de projetos realizados - sete em um ano letivo (oito meses). Assim, foi possível que, para cada atividade, com cerca de um mês de duração, fosse efetuado o lançamento do edital, as pesquisas, as apresentações individuais, os seminários de apresentação coletiva e o desenvolvimento do projeto, majoritariamente realizado em sala de aula.

A facilidade, a velocidade e o acúmulo de informações disponibilizadas na web foram fundamentais para o processo de ensino-aprendizagem, uma vez que, com as pesquisas, foi possível ampliar diretamente o repertório individual, enriquecendo as apresentações dos seminários e valorizando o coletivo, como evidenciaram os diferentes resultados apresentados. É importante ressaltar, também, que os seminários favoreceram o desenvolvimento da expressão oral, a aquisição de vocabulário técnico e o treinamento do estudante para argumentar e defender sua proposta em público.

A necessidade de utilizar outros softwares durante as atividades de projeto também serviu para que os alunos pudessem ampliar suas descobertas diante do universo digital. A utilização de novos softwares constituiu novas possibilidades de representação da forma, assim como de novos conhecimentos, com diferentes abordagens sobre o emprego da geometria, especialmente com relação à construção de curvas e superfícies.

A experiência adquirida através da disciplina foi considerada muito positiva e encorajadora pelos professores, que entenderam que o processo trouxe resultados dentro do esperado, em alguns casos, superando as expectativas para uma disciplina inicial de projeto.
Figura 15: Coberturas com superfícies complexas

Fonte: Trabalho das alunas lasmine Leal (à esquerda) e Isadora Silva (à direita). 
Em função dos resultados alcançados, foi definido, para o ano letivo de 2017, um Ateliê Digital Integrado (vertical), com alunos ingressantes em Ateliê I e "veteranos" de Ateliê II, ambos no mesmo espaço físico e com a mesma metodologia. Deve ser observado que todos os alunos concluintes da disciplina Ateliê I de 2016 se manifestaram de forma positiva quanto à metodologia empregada, e se matricularam no Ateliê Digital Integrado.

Como demonstrado, a ampla utilização do computador nas disciplinas de projeto desde as séries iniciais pode apresentar um novo olhar sobre o ensino, potencializando as experimentações necessárias do aluno perante as atividades solicitadas; aproximando o projeto da realidade, especialmente se houver comprometimento entre os agentes, pela dinamização e evolução da metodologia; repensando sobre novas abordagens e incorporando novas ferramentas. Por fim, é importante observar que, devido às rápidas transformações da sociedade atual, as metodologias de ensino das atividades de projeto devem ser atualizadas, incorporando novas demandas e recursos tecnológicos disponíveis.

\section{AGRADECIMENTOS}

À Fundação de Amparo à Pesquisa do Estado do Mato Grosso (Fapemat), pela concessão da bolsa de estudo ao primeiro autor, e aos alunos da turma Ateliê I, ano de 2016, por suas participações no curso e cessão das imagens para a publicação deste artigo.

\section{REFERÊNCIAS}

ANDRADE, V. H. M.; AMORIM, A. L.; PEREIRA, G. C. Ensino de projeto arquitetônico e CAD: uma experiência piloto. In: SIMPÓSIO DE COMPUTAÇÃO GRÁFICA EM ARQUITETURA, ENGENHARIAS E ÁREAS AFINS, 2., 1994, Salvador. Anais... Salvador: UFBA, 1994. p. 143-148.

BROADBENT, G. Diseño arquitectónico: arquitectura y ciencias humanas. Barcelona: Gustavo Gili, 1973. 463 p.

CARSALADE, F. Referências metodológicas para um processo de ensino de projeto In: LARA, F.; MARQUES, S. (Org.). Desafios e conquistas da pesquisa e do ensino de projeto. Rio de Janeiro: Virtual Científica, 2003. p. 145-158.

CELANI, G. A importância da pesquisa na formação de docentes: o caso da "informática aplicada à arquitetura e urbanismo". Cadernos de Pós-Graduação em Arquitetura e Urbanismo, São Paulo, v. 7, n. 1, 2007. Não paginada. Disponível em: <https://goo.gl/2s5Mdn>. Acesso em: 9 jan. 2018.

EASTMAN, C. M. Building product models: computer environment supporting design and construction. Boca Raton: CRC Press, 1999. $411 \mathrm{p}$

FARRAG, C.; BRAGA, G. P., TEIXERA, P. Investigação de metodologia de ensino de informática aplicada à arquitetura. In: CONGRESSO DA SOCIEDADE
IBEROAMERICANA DE GRÁFICA DIGITAL, 4., 2000, Rio de Janeiro. Anais... Rio de Janeiro: CumlnCAD, 2000. p. 1-3. Disponível em: <https://goo.gl/JmPoqR>. Acesso em: 9 jan. 2018.

FLORIO, W. Modelagem paramétrica, criatividade e projeto: duas experiências com estudantes de arquitetura. Gestão e Tecnologia de Projetos, São Carlos, v. 6 , n. 2, p. 43-66, dez. 2011. Disponível em: <https://goo.gl/Lq4Q48>. Acesso em: 9 jan. 2018.

FLORIO, W. O croqui no atelier de projeto: desafios no ensino de arquitetura na era digital. Revista Brasileira de Expressão Gráfica, [S.I.], v. 1, n. 1, p. 50-76, 2013. Disponível em: <https://goo.gl/49CXAc>. Acesso em: 9 jan. 2018.

JANOT, L. F. Metodologia de ensino: projeto de arquitetura e urbanismo. In: ANDRADE, L.; BRONSTEIN, L.; SILLOS, J. (Org.). Arquitetura e ensino: reflexões para uma reforma curricular. Rio de Janeiro: FAUUFRJ, 2003. p. 126-128.

KOLAREVIC. B. Architecture in the digital age: design and manufaturing. New York: Spon Press, 2003. 314 p.

KOWALTOWSKI, D. et al. 0 processo criativo: relacionando a teoria à prática no ensino do projeto arquitetônico. Campinas: Unicamp, 2000. Disponível em: <https:// goo.gl/4HnfJg>. Acesso em: 9 jan. 2018. 
LAWSON, B. Como arquitetos e designers pensam. Tradução Maria Beatriz Medina. São Paulo: Oficina de Textos, 2011. 296 p.

MALARD, M. L. Alguns problemas de projeto ou de ensino de arquitetura. In: LARA, F.; MARQUES, S. (Org.). Cinco textos sobre arquitetura. Belo Horizonte: UFMG, 2005. p. 80-114.

MITCHELL, W. J. A lógica da arquitetura. Tradução Gabriela Celani. Campinas: Unicamp, 2010.

NARDELLI, E. S. Arquitetura e projeto na era digital. Arquitetura Revista, Porto Alegre, v. 3, n. 1, p. 28-36, 2007. Disponível em: <https://goo.gl/TdKmDM>. Acesso em: 9 jan. 2018.

NEVES, L. P. A adoção do partido na arquitetura. Salvador: Edufba, 1998.

OXMAN, R. Digital architecture as a challenge for design pedagogy: theory, knowledge, models and medium. Design Studies, Amsterdam, v. 9, n. 2, p. 99-120, 2008. Disponível em: <https://goo.gl/ Z6RNPh>. Acesso em: 9 jan. 2018.

ROWE, P. G. Design thinking. Massachusetts: MIT Press, 1987. 229 p.

SERRA, G. G. Pesquisa em arquitetura e urbanismo: guia prático para o trabalho de pesquisadores em pós-graduação. São Paulo: Edusp: Mandarim, 2006. 256 p.
SILVA, A. B. A. et al. Trajetória de aprendizagem em representação gráfica digital. Revista Educação Gráfica, Bauru, v. 16, n. 2, p. 5-21, 2012. Disponivel em: <https://goo.gl/YvNd1n>. Acesso em: 9 jan. 2018.

SILVA, E. Novos e velhos conceitos no ensino de projeto arquitetônico. In: LARA, F.; MARQUES, S. (Org.). Desafios e conquistas da pesquisa e do ensino de projeto. Rio de janeiro: Virtual Científica, 2003. p. 32-35.

. Crítica e avaliação no ensino do projeto arquitetônico: subsídios para uma discussão necessária. In: DUARTE, C. et al. (Org.). O lugar do projeto no ensino e na pesquisa em arquitetura e urbanismo. Rio de Janeiro: Contracapa, 2007. p. 141-147.

TRAMONTANO, M. Quando pesquisa e ensino se conectam: design paramétrico, fabricação digital e projeto de arquitetura. In: CONGRESSO DA SOCIEDADE IBEROAMERICANA DE GRÁFICA DIGITAL, 19., nov. 2015, Florianópolis. Anais... São Paulo: Blucher, 2015. p. 544550. Disponível em: <https://goo.gl/53brtV>. Acesso em: 9 jan. 2018.

VARGAS, H. C. Ensino/aprendizagem em arquitetura e urbanismo: mitos e métodos. In: SEMINÁRIO DE ENSINO E PESQUISA EM PROJETO DE ARQUITETURA, 2., nov. 2005, Rio de Janeiro. Anais... Rio de Janeiro: PROARQ: FAU-UFRJ, 2005. Não paginado. Disponivel em: <https://goo.gl/zq2md8>. Acesso em: 9 jan. 2018. Sérgio Dias Maciel
sdmac@terra.com.br

Arivaldo Leão de Amorim alamorim@ufba.br

Érica de Sousa Checcucci erica_checcucci@ufba.br 
